\title{
Health and Socio-economic Implications of Poverty in Bangladesh
}

\author{
Sacchidanand Majumder (PhD Fellow) \\ Soma Chowdhury Biswas (PhD, Professor)
}

Department of Statistics, University of Chittagong, Bangladesh

Doi:10.19044/esj.2018.v14n29p301 URL:http://dx.doi.org/10.19044/esj.2018.v14n29p301

\begin{abstract}
The objective of this study was to explore the influences of the health and socio-economic factors associated with the poverty level of households in Bangladesh, through an analysis of data from the Household Income and Expenditure Survey (HIES) 2010 conducted by Bangladesh Bureau of Statistics (BBS). A total of all 12,240 households was considered in this study. CBN method was applied for estimating poverty of the household. A logistic regression analysis was used to identify the main factors that influence the household's poverty. The results showed that the probability of the household being poor was higher when the household's head suffered from various chronic diseases like chronic fever, injuries/disability, eczema, leprosy, and asthma/breathing trouble as compared to the household whose head didn't suffer from any chronic diseases. From the analysis, it was also found that when a large number within household suffered from any chronic disease, the probability of the household being poor was increased. The household that had no access to health care was poorer than the household that had access to health care. The results also showed that with increased investment in health, the probability of the household being poor was decreased. The results showed that rural households were poorer than urban households. Monthly income, land ownership, construction materials of walls and roofs, types of the latrine, source of drinking water, household size; age, sex, and employment status of the household's head all had a significant impact on the poverty level of the household.
\end{abstract}

Keywords: Health, Poverty, Logistic regression analysis, Household, Bangladesh.

\section{Introduction}

Poverty is a multi-dimensional concept. Among other things, it includes a lack of access to sufficient health services and sanitation, a high degree of 
illiteracy, insufficient income, and scarcity of basic rights and security. This multi-faceted concept of human deprivation interacts in many significant ways, e.g., good health leads to higher productivity and improves the performance and results in increased incomes.

Health is an essential human right, a societal asset, and a necessity in order to live, work and income (World Bank, 2004). Health is a catalyst and a critical ingredient for achieving economic, social and environmental goals, including poverty alleviation and economic growth. Poor health is a source of impoverishment among households in low-income and middle-income countries. The trajectories of low-income households are often decisively shaped by ill-health, injury and premature death (Pryer, 1993). Ill health produces poverty and hinders economic growth, while poverty drives ill health in low-income, middle-income, and high-income countries alike (Deaton, 2016), creating a vicious cycle.

An important cause of poverty in low and middle- income countries is the death or severe illness of a family's main income earner. Out of 125 case studies summarized in the World Bank's publication titled, voices of the poorcrying out for change that illness, injury or death was the most common trigger of households' impoverishment (Narayan, Chambers, Shah \& Petesch, 2000).

The illness of the main earner in low and middle- income countries significantly reduces the overall household income. People who have chronic diseases are not fully able to compensate for income lost during the periods of illness when they are back to relatively good health (Kochar, 2004).

The link between poverty and health is well established worldwide, the connection is both direct (lack of access to health services) and indirect (lack of awareness about health-related issues). Poverty aggravates ailments and illhealth pushes people towards poverty. It is a vicious cycle. Socioeconomic conditions create situations that can lead to ill-health. Health emergencies can cost individuals and families dearly, thus aggravating poverty (Hafeez, 2014).

Links between ill-health and poverty may strengthen over time, and the direction of causality can be difficult to discern. The literature on "chronic poverty" recognizes the dynamic and heterogeneous nature of deprivation, and among chronically poor households, ill-health may be ".... consequence of poverty as well as a predictive factor" (Mitlin, 2005).

In Bangladesh, the households that moved into the status "always poor", all reported death or severely disabling diseases as one of the main causes. Chronic diseases inflict an enormous direct and indirect economic burden on the poor and push many people and their families into poverty. Existing knowledge underestimates the implications of chronic diseases for poverty and the potential that chronic disease prevention and health promotion have for alleviating poverty in low and middle- income countries (Hulme \& Shepherd, 2003). 
The fact that an adult family member has a chronic disease can also have direct health implications for children. According to a study in Bangladesh, for example, the relative risk of a severely malnourished child coming from a household with an incapacitated income earner is 2.5 times greater than that of households which are not in such a situation (Roy, Kane \& Khuda, 2001).

The study conducted by the Northern Ireland Statistics \& Research Agency (2005) indicates that poverty relates to the incidence of long- term illness. Individuals with a limiting long-term illness are at a greater risk of poverty $(40 \%)$ than those who have no limiting long-term illness $(21 \%)$. Some 31 percent of all individuals have a liming long-term illness and 69 percent do not. Persons in poverty are more likely to have a limiting long-term illness $(46 \%)$ and this is significantly more than individuals not in poverty $(25 \%)$.

Ill-health is frequently a risk factor for poverty, and it may prolong the duration of impoverishment. Life history research in rural Bangladesh showed how health shocks could prove critical in the persistence of poverty (Hulme, 2004).

Of the few empirical pieces that have focused on the impact of ill health, Jalan and Ravallion (1998) for rural China, found the ill health of household members to be an important determinant for chronic poverty, but not transient poverty. Sen (2003) for Bangladesh, using panel data, also found sickness to be particularly important as a factor associated with transient (movements into) poverty whilst Dercon (2003), for Ethiopia, also found the poor to suffer disproportionately from health shocks.

Poverty and disease are indivisible and there are a variety of linkages between them (Schwefel, Vučković, Korte, \& Brandrup-Lukanow, 2004). Worldwide, 1.6 billion people live in transition countries without adequate and affordable access to health services. These populations go without preventative or primary care, lifesaving medicines or advanced medical care (Prekar, Langenbrunner, \& Jakab, 2002). In Jamaica, 59\% of the people with chronic diseases experienced financial difficulties because of their illness, and as a result, a high proportion of people admitting such difficulties avoided some type of medical treatment (Henry \& Yearwood, 1999).

Inadequate access to good-quality health services, including diagnostic and clinical prevention services, is a significant cause of the social and economic inequalities in the burden of chronic diseases. The poor face several health-care barriers including financial constraints, lack of proximity and/or availability of transport to health-care centers and poor responsiveness from the health-care system (Goddard \& Smith, 1998; Lorant, Boland, \& Humblet, 2002).

Investing in health improves health outcomes and arrests the vicious cycle of poverty and illness. Investing in health may ultimately impact macroeconomic growth and other important economic indicators (Floud, 
Fogel, Bernard, \& Sok, 2011). A rich, long-standing literature explores the relationship between health and the economy, with many economists contending that health fuels economic growth (Fogel, 1994; Gallup \& Sachs, 2001; Sachs, 2001; Bloom, Canning, \& Sevilla, 2004).

The relationship between poverty, the social determinants, and health has been extensively studied and analyzed: the impoverished often live in poor conditions, without proper access to water, sanitation, food security or decent housing. Conversely, improved health plays a role both at an individual, household and societal level in reducing poverty, ultimately boosting economic growth. Investing in health systems can improve health outcomes, and also break the vicious circle of poverty and poor health (Wagstaff, 1987; World Health Organization, 2001).

At the microeconomic level, several studies support the conclusions of macroeconomic studies on the mechanisms through which health affects both the economy and poverty reduction (Miguel \& Kremer, 2004; Almond, 2006; Bleakley, 2007; Almond, Lena, \& Mårten, 2009; Field, Omar, \& Maximo, 2009; Kremer, Leino, Miguel, \& Zwane, 2011).

The objective of this study was to explore the influences of the health and socio-economic factors associated with the poverty status of households in Bangladesh.

\section{Methodologies \\ Source of Data}

The data utilized for the present study were picked out from the Household Income and Expenditure Survey (HIES) 2010, which is a nationally representative survey conducted by the Bangladesh Bureau of Statistics (BBS). A two-stage stratified random sampling technique was followed in drawing the sample of HIES 2010 under the framework of the Integrated Multipurpose Sample (IMPS) design developed on the basis of the sampling frame based on the Population and Housing Census 2001. The IMPS design consisted of 1000 Primary Sampling Units (PSUs) throughout the country. There were 640 rural and 360 urban PSUs in the sample. The PSU was defined as contiguous two of more enumeration areas (EA) used in Population and Housing Census 2001. Each PSU comprised of around 200 households. In the first stage, about one half, 612 in exact, out of total 1000 IMPS PSUs, were drawn. These PSUs were selected from 16 different strata. There were 6 rural, 6 urban and 4 SMA strata. In the second stage, 20 households were selected from each of the rural PSUs and also the PSUs located in the municipal areas and SMAs. Thus, the HIES is a sub-set of IMPS. In HIES-2010, a total of 12240 households were selected where 7840 from rural area and 4400 from urban area. 


\section{Cost of Basic Need Method}

For determining the poverty level of the household as a dependent variable, the Cost of Basic Needs $(\mathrm{CBN})$ method is used as the standard method for estimating the incidence of poverty. In this method, two poverty lines are estimated:

\section{Lower poverty line \\ II. Upper poverty line}

A brief description of estimating the incidence of poverty using the CBN method is as follows:

\section{A. Food poverty line}

1. A basic food basket (eleven food items) was selected. The food basket consisted of eleven items; rice, wheat, pulses, milk, oil, meat, fish, potato, other vegetables, sugar and fruits, as recommended by Ravallion and Sen (1996), based on Alamgir (1974).

2. The quantities in the basket were scaled according to the nutritional requirement of $2,122 \mathrm{k}$.cal per person per day.

3. The price of each item in the basket was estimated as the mean of unit values (price per unit) of the item reported by a reference group of households, calculated separately for each of the 16 geographic areas or strata. The food poverty line (FPL) was computed by multiplying the prices with the quantities in the food basket.

\section{B. Non-food poverty line}

A non-food poverty line was calculated by estimating the cost of consuming non-food items by the households close to the food poverty line. The first was obtained by taking the median amount spent on non-food items by a group of households whose per capita total expenditure is close to the food poverty line, which is called the "lower non-food allowance" The second was obtained by taking the median amount spent for non-food items by group of household whose per capita food expenditure is close to the food poverty line, which is called the "upper non-food allowance".

\section{Lower Poverty Line}

The lower poverty line is estimated by adding to the food poverty line and lower non-food allowance for each of the 16 geographical areas.

\section{Upper Poverty Line}

The upper poverty line is estimated by adding to the food poverty line and upper non-food allowance for each of the 16 geographical areas. 


\section{Logistic Regression Model}

To identify determinants of poverty we first computed a dichotomous variable indicating whether the household is poor or non-poor. That is, Poverty Level of Household $= \begin{cases}0, & \text { if the household is non }- \text { poor } \\ 1, & \text { if the household is poor }\end{cases}$

Here, for estimating the poverty level of the household, the Cost of Basic Need (CBN) method was used in this study.

On the basis of Pearson's Chi-square statistic, we determine whether the predictors household size, age of household's head, sex of household's head, household's head suffering from chronic disease, number of household's members suffering from chronic disease, number of household's members suffering from any symptoms of illness in last 30 days, household access to health care for receiving treatment, monthly expenditure on health, employment status of household, monthly income of household, land ownership, construction materials of walls, construction materials of roofs, type of latrine, source of drinking water, division of residence and place of residence were associated with the poverty of household.

Then, we used a logistic regression model, given by

$$
\operatorname{logit}(P)=\log \left(\frac{P}{1-P}\right)=\sum_{i} \beta_{i} X_{i}=\beta_{0}+\beta_{1} X_{1}+\beta_{2} X_{2}+\cdots \cdots \cdots \cdots+\beta_{17} X_{17}
$$

where $X_{1}, X_{2}, X_{3} \cdots \cdots \cdots \cdots \cdots \cdots, X_{17}$ were the predictor variables, i.e., household size, age of household's head, sex of household's head, household's head suffering from chronic disease, number of household's members suffering from chronic disease, number of household's members suffering from any symptoms of illness in last 30 days, household access to health care for receiving treatment, monthly expenditure on health, employment status of household, monthly income of household, land ownership, construction materials of walls, construction materials of roofs, type of latrine, source of drinking water, division of residence and place of residence respectively and $p$ denoted the probability that the household was poor.

For the study purpose, Stepwise (forward- conditional) method of binary logistic regression analysis is used.

\section{Results of Logistic Regression Analysis and Discussion}

Table 1 presents the result of the logistic regression model using both upper and lower poverty line separately. In the present analysis, non-poor of the household category of the outcome variable $(\mathrm{Y}=0)$ has been considered as the reference category of the dependent variable.

The results of the logistic analysis shown in table 1 that using upper and lower poverty line, the household with 3-4 members, 5-6 members, and 7 and more members are $2.777,8.414 \& 27.001$ times and 2.320, $7.119 \& 23.984$ times more likely be poor respectively as compared with the households with 
1-2 members. Again, using both upper and lower poverty line, the results illustrate that the female-headed households are 1.383 and 1.454 times more likely to be poor respectively than the male-headed households.

The logistic regression model displays that the households whose head suffered from different types of chronic disease (like as Chronic fever, Injuries/Disability, Eczema, Leprosy, Asthma/ Breathing trouble) are more times likely to be poor as compared to the households whose head didn't suffer from any types of chronic disease in both upper and lower poverty line. It is also revealed that using both poverty lines, the probability of the household being poor is higher when a large number within the household suffered from any types of chronic disease. Using both upper and lower poverty line, the result shows that the households whose 4 and more members suffered from any chronic disease are 2.084 and 2.558 times more likely to be poor respectively as compared to the households whose nobody suffered from any chronic disease. From the results of regression analysis, it is revealed that the households whose anybody suffered from any symptom of illness in last 30 days are more likely to be poor as compared to those with nobody suffered from any symptom of illness in last 30 days in upper poverty lines. 


\begin{tabular}{|c|c|c|c|c|c|c|c|c|c|c|c|c|}
\hline \multirow{3}{*}{ Variable } & \multicolumn{6}{|c|}{ Upper Poverty Line } & \multicolumn{6}{|c|}{ Lower Poverty Line } \\
\hline & Coefficient & S.E & $P$ & Odds & $95 \%$ C.I & $\mathrm{r} \operatorname{EXP}(\beta)$ & Coefficient & S.E. & $P$ & Odds & $95 \%$ C.I. & $\operatorname{rEXP}(\beta)$ \\
\hline & & & & ratio & Lower & Upper & & & & & Lower & Upper \\
\hline Household Size & & & & & & & & & & & & \\
\hline 1-2 members (RC) & & & .000 & 1.000 & & & & & .000 & 1.000 & & \\
\hline 3-4 members & 1.021 & .126 & .000 & 2.777 & 2.170 & 3.554 & .842 & .167 & .000 & 2.320 & 1.672 & 3.218 \\
\hline 5-6 members & 2.130 & .128 & .000 & 8.414 & 6.548 & 10.812 & 1.963 & .168 & .000 & 7.119 & 5.124 & 9.889 \\
\hline 7 and more members & 3.296 & .137 & .000 & 27.001 & 20.632 & 35.337 & 3.177 & .176 & .000 & 23.984 & 16.998 & 33.841 \\
\hline Age of Household Head & & & & & & & & & & & & \\
\hline Less than aged $35(\mathrm{RC})$ & & & .000 & 1.000 & & & & & .000 & 1.000 & & \\
\hline Aged 35-44 & -.240 & .061 & .000 & .786 & .698 & .886 & -.269 & .071 & .000 & .764 & .665 & .878 \\
\hline Aged 45-59 & -.467 & .063 & .000 & .627 & .554 & .709 & -.485 & .075 & .000 & .615 & .531 & .713 \\
\hline Aged 60 and above & -.152 & .077 & .047 & .859 & .739 & .998 & -.137 & .091 & .131 & .872 & .730 & 1.042 \\
\hline Sex of Household's Head & & & & & & & & & & & & \\
\hline Male (RC) & & & & 1.000 & & & & & & 1.000 & & \\
\hline Female & .325 & .089 & .000 & 1.383 & 1.161 & 1.649 & .375 & .109 & .001 & 1.454 & 1.175 & 1.800 \\
\hline Household's head suffered & from chronic & IIness & & & & & & & & & & \\
\hline Not suffered (RC) & & & .003 & 1.000 & & & & & .000 & 1.000 & & \\
\hline Chronic fever & .275 & .230 & .230 & 1.317 & .840 & 2.065 & .554 & .254 & .029 & 1.741 & 1.059 & 2.863 \\
\hline Injuries/Disability & .457 & .177 & .010 & 1.579 & 1.116 & 2.233 & .256 & .196 & .191 & 1.291 & .880 & 1.894 \\
\hline Eczema & .606 & .362 & .094 & 1.833 & .903 & 3.724 & .874 & .372 & .019 & 2.397 & 1.155 & 4.974 \\
\hline Leprosy & 1.195 & .663 & .072 & 3.302 & .901 & 12.108 & 2.117 & .673 & .002 & 8.306 & 2.219 & 31.086 \\
\hline $\begin{array}{l}\text { Asthma/ Breathing } \\
\text { trouble }\end{array}$ & .349 & .140 & .012 & 1.418 & 1.078 & 1.864 & .121 & .168 & .472 & 1.129 & .812 & 1.570 \\
\hline Others & -.007 & .067 & .913 & .993 & .870 & 1.132 & -.206 & .081 & .011 & .814 & .694 & .955 \\
\hline Number of household's me & mbers suffere & from & hronic i & Iness & & & & & & & & \\
\hline No member (RC) & & & .000 & 1.000 & & & & & .000 & 1.000 & & \\
\hline $1-3$ members & -.388 & .057 & .000 & .678 & .607 & .758 & -.215 & .067 & .001 & .806 & .708 & .919 \\
\hline 4 and more members & .734 & .260 & .005 & 2.084 & 1.252 & 3.471 & .939 & .263 & .000 & 2.558 & 1.529 & 4.281 \\
\hline Number of household's me & embers suffere & from & ny sym & toms of $\mathrm{i}$ & ness in la & 0 days & & & & & & \\
\hline No member (RC) & & & .005 & 1.000 & & & & & & & & \\
\hline $1-3$ members & .518 & .185 & .005 & 1.678 & 1.167 & 2.413 & & & & & & \\
\hline 4 and more members & .327 & .212 & .123 & 1.387 & .915 & 2.103 & & & & & & \\
\hline Household access to health & care for recei & ing tre & tment & & & & & & & & & \\
\hline Yes (RC) & & & & 1.000 & & & & & & 1.000 & & \\
\hline No & .387 & .062 & .000 & 1.473 & 1.304 & 1.665 & .298 & .075 & .000 & 1.347 & 1.164 & 1.559 \\
\hline Monthly expenditure on he & alth & & & & & & & & & & & \\
\hline No cost (RC) & & & .000 & 1.000 & & & & & .000 & 1.000 & & \\
\hline Less than Tk. 1000 & -.416 & .186 & .026 & .660 & .458 & .951 & .032 & .067 & .621 & .992 & .905 & 1.179 \\
\hline Tk. $1000-5000$ & -.804 & .194 & .000 & .447 & .306 & .655 & -.238 & .097 & .014 & .788 & .652 & .953 \\
\hline Above Tk. 5000 & -1.085 & .233 & .000 & .338 & .214 & .534 & -.740 & .198 & .000 & .477 & .324 & .703 \\
\hline Employment status of hous & ehold's head & & & & & & & & & & & \\
\hline Unemployed (RC) & & & .000 & 1.000 & & & & & .000 & 1.000 & & \\
\hline Daily labour & .877 & .086 & .000 & 2.403 & 2.032 & 2.841 & .794 & .104 & .000 & 2.212 & 1.805 & 2.710 \\
\hline Self-employed/ employer & -.015 & .084 & .857 & .985 & .835 & 1.162 & -.021 & .105 & .844 & .980 & .798 & 1.203 \\
\hline Employee & .178 & .099 & .073 & 1.194 & .984 & 1.450 & .195 & .126 & .122 & 1.215 & .949 & 1.556 \\
\hline Monthly Income of Housel & hold & & & & & & & & & & & \\
\hline $\begin{array}{l}\text { Less than Tk. } 10,000 \\
\text { (RC) }\end{array}$ & & & .000 & 1.000 & & & & & .000 & 1.000 & & \\
\hline Tk. $10,000-20,000$ & -1.282 & .056 & .000 & .278 & .249 & .310 & -1.196 & .072 & .000 & .302 & .263 & .348 \\
\hline Above Tk. 20,000 & -2.176 & .097 & .000 & .114 & .094 & .137 & -2.409 & .158 & .000 & .090 & .066 & .122 \\
\hline Land ownership of househ & & & & & & & & & & & & \\
\hline No Land (RC) & & & .000 & 1.000 & & & & & .000 & 1.000 & & \\
\hline Less than 0.5 acre & -.218 & .104 & .037 & .804 & .655 & .987 & -.376 & .126 & .003 & .686 & .536 & .879 \\
\hline 0.5 acre and more & -.879 & .108 & .000 & .415 & .336 & .513 & -1.176 & .132 & .000 & .308 & .238 & .399 \\
\hline Dwelling construction mat & erials of the $w$ & Ils of $t$ & e main & oom & & & & & & & & \\
\hline Brick/ cement (RC) & & & & 1.000 & & & & & & 1.000 & & \\
\hline Non-brick/ cement & .911 & .071 & .000 & 2.488 & 2.166 & 2.858 & 1.348 & .114 & .000 & 3.851 & 3.082 & 4.813 \\
\hline Dwelling construction me & erials of the & f of th & main $\mathrm{rc}$ & & & & & & & & & \\
\hline Brick/ cement (RC) & & & & 1.000 & & & & & & 1.000 & & \\
\hline Non-brick/ cement & .817 & 133 & .000 & 2.264 & 1.743 & 2.941 & .945 & .246 & .000 & 2.572 & 1.588 & 4.167 \\
\hline Type of latrine used by hou & isehold & & & & & & & & & & & \\
\hline Hygienic (RC) & & & & 1.000 & & & & & & 1.000 & & \\
\hline Unhygienic & .181 & .051 & .000 & 1.199 & 1.086 & 1.324 & .208 & .063 & .001 & 1.232 & 1.089 & 1.393 \\
\hline Source of drinking $w$ & & & & & & & & & & & & \\
\hline Supply water (RC) & & & .000 & 1.000 & & & & & .000 & 1.000 & & \\
\hline Tube well & .351 & .099 & .000 & 1.421 & 1.170 & 1.726 & .821 & .172 & .000 & 2.274 & 1.622 & 3.188 \\
\hline Others & .737 & .142 & .000 & 2.089 & 1.581 & 2.761 & .983 & .213 & .000 & 2.673 & 1.760 & 4.059 \\
\hline Division of residence & & & & & & & & & & & & \\
\hline Barisal (RC) & & & .000 & 1.000 & & & & & .000 & 1.000 & & \\
\hline Dhaka & -.688 & .095 & .000 & .503 & .418 & .605 & -1.062 & .108 & .000 & .346 & .280 & .427 \\
\hline Chittagong & -.037 & .088 & .670 & .963 & .810 & 1.145 & -.371 & .098 & .000 & .690 & .570 & .836 \\
\hline Khulna & -.156 & .101 & .121 & .856 & .703 & 1.042 & -.554 & .115 & .000 & .575 & .458 & .721 \\
\hline Rajshahi & -.269 & .099 & .007 & .764 & .629 & .928 & -.483 & .113 & .000 & .617 & .495 & .770 \\
\hline Rangpur & .171 & .100 & .089 & 1.186 & .974 & 1.444 & .070 & .110 & .524 & 1.072 & .865 & 1.329 \\
\hline Sylhet & -.897 & .119 & .000 & .408 & .323 & .515 & -.691 & .130 & .000 & .501 & .388 & .647 \\
\hline Place of residence & & & & & & & & & & & & \\
\hline Rural (RC) & & & & & & & & & & 1.000 & & \\
\hline Urban & & & & & & & -.594 & .080 & .000 & .552 & .472 & .646 \\
\hline & & & & & & rmatic & & & & & & \\
\hline & $\begin{array}{r}-2 \text { Log likel } \\
13878.9\end{array}$ & lood & $\begin{array}{r}\text { Chi- } \\
13\end{array}$ & $\begin{array}{l}\text { quare } \\
968\end{array}$ & $\begin{array}{l}\mathrm{df} \\
8\end{array}$ & $\begin{array}{l}\text { Sig. } \\
.083\end{array}$ & $\begin{array}{r}-2 \text { Log likel } \\
10273.7\end{array}$ & $\begin{array}{l}\text { hood } \\
7\end{array}$ & $\begin{array}{r}\text { Chi- } \\
13\end{array}$ & $\begin{array}{l}\text { quare } \\
044\end{array}$ & $\begin{array}{l}\mathrm{df} \\
8\end{array}$ & $\begin{array}{l}\text { Sig. } \\
.110\end{array}$ \\
\hline
\end{tabular}

$\mathrm{RC}=$ Reference Category 
The logistic model indicates that using upper and lower poverty line, the households that have no access to health care for receiving treatment are 1.473 and 1.347 times more likely to be poor respectively as compared to the households that have access to health care for receiving treatment. The multivariate results show that using both upper and lower poverty lines, the households whose head is daily laborer and employee are poorer than the household whose head is unemployed.

The results illustrate that using both upper and lower poverty lines, the households who have non-bricked/cemented walls of the main room are 2.488 and 3.851 times more likely to be poor respectively as compared to those who live with bricked/cemented walls. Again, using both upper and lower poverty lines, the households with non-bricked/cemented roofs of the main room are 2.264 and 2.572 times more likely to be poor respectively as compared to those have bricked/cemented roofs. From the results of the logistic analysis, it is found that the households who have access to hygienic latrines are 1.199 and 1.232 times more likely to be poor respectively in both poverty lines as compared to the households who have no access to the hygienic latrine. Further, using both upper and lower poverty lines, the households who have access to tube-well as a source of drinking water and other sources of drinking water are $1.421 \& 2.089$ and $2.274 \& 2.673$ times more likely to be poor respectively as compared to the households who have access to supply water as a source of drinking water. Regional variations are marked with respect to household's poverty. The logistic result shows that using upper poverty line, the household that lives in Sylhet is comparatively less poor (Odds ratio: 0.408) and using lower poverty line, the household that lives in Dhaka is comparatively less poor (Odds ratio: 0.348) than all the other divisions. Again, in both poverty lines, the household that lives in Rangpur are poorer than the household that lives in other divisions.

The results also indicate that using both upper and lower poverty lines, the households whose head belongs to the age groups 35-44, age 45-59 and age $60 \&$ above are $0.786,0.627 \& 0.859$ times and $0.764,0.615 \& 0.872$ times less likely to be poor as compared to the households whose head belongs to age less than 35. From the results of the logistic analysis, it is observed that for increasing investment in health, the probability of a household being poor is gradually decreased in both poverty lines. Using both upper and lower poverty lines, the odds ratio mentions that the households who spent monthly less than Tk.1000, Tk.1000-5000, and above Tk.5000 for health purpose are $0.660,0.447, \& 0.337$ times and $0.992,0.788 \& 0.477$ times less likely to be poor respectively as compared to the households who have no expenditure for health purpose.

The results illustrate that using both the poverty lines; the probability of the household being poor is gradually decreased when the monthly income of 
the household is increased. Using both upper and lower poverty lines, the odds ratio indicates that the households whose monthly income is Tk.10000-20000, and above Tk.20000 are $0.278 \& 0.114$ times and $0.302 \& 0.090$ times less likely to be poor respectively as compared to those whose monthly income is less than Tk.10,000. Furthermore, using both upper and lower poverty lines, the probability of the household being poor is decreased gradually with increasing land ownership of the household. The households who have owned less than 0.5 acres and above 0.5 acres land are $0.804 \& 0.415$ times and 0.686 $\& 0.308$ times less likely to be poor respectively as compared to those have no land. Using the lower poverty line, the logistic model shows that the urban households are less poor (Odds ratio: 0.552 ) than the rural households.

From the above-mentioned discussion, the present study provides information that there exists a strong and effective association between poverty and health and socio-economic variables.

\section{Conclusion and Recommendation}

Health and socio-economic issues are directly or indirectly related to a household's poverty status. This study was done to estimate the effect of health on poverty in Bangladesh. The data used for this study was taken from the Household Income and Expenditure Survey (HIES) 2010 conducted by BBS. Cost of Basic Need (CBN) method was applied for estimating the poverty of a household.

The result of the logistic analysis shows that with increased household size, the probability of a household being poor is gradually increased. The study findings display that female-headed household is poorer than maleheaded household.

Using both poverty lines, the multivariate analysis shows that the probability of a household being poor is higher when the household's head suffered from various chronic diseases like chronic fever, injuries/disability, eczema, leprosy, and asthma/breathing trouble as compared to the household whose head didn't suffer from any chronic disease. From the analysis, it is also found that when a large number within household suffered from any chronic disease, the probability of the household being poor is more as compared to when nobody and a few numbers within household suffered from any chronic disease. The result of the multivariate analysis indicates that with an increased number of a household's member suffering from any symptom of illness in the last 30 days, the probability of the household being poor is increased. It is found that the households who have no access to health care are more times poor as compared to the households who have access to healthcare. The results also show that with increased investment in health, the probability of the household being poor is decreased. So, increasing investment in health can lead a household from being poor to non-poor. 
The study also found that daily labor-headed households, and the employee-headed households are poorer than the unemployed-headed household. The study shows that the household with low quality of construction materials of walls and roof, and poor sanitation facilities and source of drinking water are poorer as compared to those who have high quality. The study result shows that rural households are poorer than urban households.

For reducing household's poverty, the present study provides some recommendations. Thus, people should be encouraged to keep their family size small, and people should be advised to use contraceptives for spacing and limiting births. Lately, the reduction in population growth in Bangladesh has become stagnant. In this situation, policy and decision makers should review the family planning programs. The employment status of the female-headed households is very important in addressing the issue of poverty. Policy-makers should continue to implement policies that create employment opportunities for females.

Chronic diseases can cause poverty in individuals and families and draw them into a downward spiral of worsening disease and poverty. The government should consider investment in chronic disease prevention programs for poor people of Bangladesh who are struggling to reduce poverty. It is important that a line item for chronic disease prevention and control should be included in the annual health budget. The poorest people experience extreme difficulties in accessing appropriate care, with devastating impacts on individuals, households and whole communities. Prioritizing health of poor and poorest in society is justifiable economically as well as ethically a healthy population is more productive and stable. In this situation, policy and decision makers should review the policies for achieving and ensuring access to healthcare service for all, especially the poor and rural people. The government and NGOs should increase easily to access health care facilities.

Health financing is an important mechanism by which the policies and plans are translated into reality. Financing decisions based on the principles of equity and effectiveness ensures adequate health care access and coverage for all. Various financing components (funding, resource allocation, contracting and reimbursement) should be used to encourage the implementation of chronic disease prevention and control policies and plans.

This pointed to the need for further investigation into the types of jobs the people who are reported to be working are involved in. A policy implication would be that it is not the number of jobs that can be a good tool to deal with poverty, but the quality of the job too. Poverty alleviation efforts should be made to improve housing and sanitation conditions and increase the provision of safe drinking water as these are found to be important reasons for poverty in a household. The government should also allot more land to landless 
households to reduce poverty in Bangladesh. Poverty alleviation efforts should also be made through grassroots-level planning to raise both farms and nonfarms rural real incomes. This can be done through job creation, micro- and small-scale entrepreneurship.

\section{References:}

1. Alamgir, M. (1974). Some Analysis of Distribution of Income, Consumption, Saving and Poverty in Bangladesh. Bangladesh Development Studies, 2, 737-818.

2. Almond, D. (2006). Is the 1918 Influenza Pandemic Over? Long-Term Effects of in Utero Influenza Exposure in the Post-1940 U.S. Population. Journal of Political Economy, 114(4), 672-712. doi:10.1086/507154.

3. Almond, D., Lena, E., \& Mårten, P. (2009). Chernobyl's Subclinical Legacy: Prenatal Exposure to Radioactive Fallout and School Outcomes in Sweden. The Quarterly Journal of Economics, 124(4), 1729-72. doi:10.1162/qjec.2009.124.4.1729.

4. Bleakley, H. (2007). Disease and Development: Evidence from Hookworm Eradication in the American South. The Quarterly Journal of Economics, 122(1), 73-117. doi:10.1162/qjec.121.1.73.

5. Bloom, D. E., David, C., \& Jaypee, S. (2004). The Effect of Health on Economic Growth: A Production Function Approach. World Development, 32(1), 1-13. doi:10.1016/j.worlddev.2003.07.002.

6. Deaton, A. (2016). On Death and Money: History, Facts, and Explanations. JAMA. doi:10.1001/jama.2016.4072

7. Dercon, S. (2003). The Impact of Economic Reforms on Rural Households in Ethiopia: A Study from 1989- 1995.World Bank.

8. Field, E., Omar, R., \& Maximo, T. (2009). Iodine Deficiency and Schooling Attainment in Tanzania. American Economic Journal: Applied Economics, 1(4), 140-69.

9. Floud, R., Fogel, R. W., Bernard H., \& Sok, C. H. (2011). The Changing Body: Health, Nutrition, and Human Development in the Western World since 1700. New York: Cambridge University Press.

10. Fogel, R. W. (1994). Economic Growth, Population Theory, and Physiology: The Bearing of Long-Term Processes on the Making of Economic Policy. The American Economic Review, 84(3), 369-395.

11. Gallup, J. L., \& Sachs, J. D. (2001). The Economic Burden of Malaria. The American Journal of Tropical Medicine and Hygiene, 64 (1\&2), 85-96.

12. Goddard, M., \& Smith, P.C. (1998). Equity of access to health care. Working Paper no. 32. Centre for Health Economics, University of York, York. 
13. Henry-Lee, A., \& Yearwood, A. (1999). Protecting the poor and the medically indigent under health insurance: a case study in Jamaica. Bethesda, MD, Partnership for Health Reform Project and Abi Associates, 1999.

14. Hulme, D., \& Shepherd, A. (2003). Conceptualizing chronic poverty. World Development, 31, 403-423.

15. Hulme, D. (2004). Thinking 'small' and the understanding of poverty: Maymana and Mofizul's story. Journal of Human Development and Capabilities, 5(2), 161-176.

16. Jalan, J., \& Ravallion, M. (1998). Determinants of Transient and Chronic Poverty Evidence from Rural China. Policy Research Working Paper Series 1936, The World Bank.

17. Kochar, A. (2004). Ill-health, savings and portfolio choices in developing countries. Journal of Developing Economics, 73, 257-285.

18. Kremer, M., Leino, J., Miguel, E., \& Zwane, A. P. (2011). Spring Cleaning: Rural Water Impacts, Valuation, and Property Rights Institutions. The Quarterly Journal of Economics, 126(1), 145-205. doi:10.1093/qje/qjq010.

19. Lorant, V., Boland, B., Humblet, P., \& Deliege, D. (2002). Equity in prevention and health care. Journal of Epidemiology and Community Health, 56, 510-516.

20. Miguel, E., \& Kremer, M. (2004). Worms: Identifying Impacts on Education and Health in the Presence of Treatment Externalities. Econometrica $72 \quad$ (1), 159-217. doi:10.1111/j.14680262.2004.00481.x.

21. Mitlin, D. (2005). Understanding chronic poverty in urban areas. International Planning Studies, 10(1), 3-19.

22. Narayan, D., Chambers, R., Shah, M., \& Petesch, P. (2000). Voices of the poor-crying out for change. Oxford University Press, New York.

23. Northern Ireland Statistics \& Research Agency (2005). Household and Individual Characteristics of those in Poverty. Bulletin No. 5.

24. Preker, A., Langenbrunner, J., \& Jakab, M. (2002). Rich-Poor Difference in Health Financing. In David M. Dror \& Alexander S. Preker (Eds), Social Reinsurance: A New Approach to Sustainable Community Health Financing (PP: 21-36). The World Bank and International Labour Organisation, Washington D.C.

25. Pryer, J. (1993). The impact of adult ill-health on household income and nutrition in Khulna, Bangladesh. Environment and Urbanization. 5(2), 35-49.

26. Ravallion, M., \& Sen, B. (1996). When Method Matters: Monitoring Poverty in Bangladesh. Economic Development and Cultural Change, 44, 761-792. 
27. Roy, N. C., Kane, T., \& Khuda, B. (2001). Socioeconomic and health implications of adults deaths in families of rural Bangladesh. Journal of Health, Population and Nutrition, 19, 291-300.

28. Schwefel, D., Vučković, M., Korte, R., Doetinchem, O., Bichmann, W., \& Brandrup-Lukanow, A. (2004). Health, Development and lobalisation. Guidelines and Recommendations for International Cooperation. GTZ/DTG/KfW/DGPH/DVGPH, Eschborn.P-9.

29. Sen, B. (2003). Drivers of Escape and Descent: Changing Household Fortunes in Rural Bangladesh. World Development, 31(3), 513-534.

30. Wagstaff, A. (1987). Government Prevention Policy and the Relevance of Social Cost Estimates. British Journal of Addiction, 82(5), 461-67. doi:10.1111/j.1360-0443.1987.tb01502.x.

31. World Bank (2004). Rising to the Challenges. Washington D.C

32. World Health Organization. (2001). Macroeconomics and Health: Investing in Health for Economic Development. Geneva, Switzerland. 